\title{
Yield Improvement Study on a Reduced Size Blank Metal Sheet for Stamping Product
}

\author{
Izwan Hamid, Sharuddin Mohd Dahuri and Syed Fahmi Syed Putra \\ Mechanical Engineering Department, Politeknik Sultan Azlan Shah, Behrang Stesyen, \\ 35950 Behrang, Perak
}

\begin{abstract}
This paper is about the reduction of the overall size of metal blanking sheet that is being used to form a stamping product or car body panel of a car manufacturer in Malaysia. The current blanking sheet produces extra waste which will be recycled and does not contribute to increase productivity but increases inventory cost. The reduction in the blanking sheet size will lead to the reduction of raw material hence reduced the production cost. However, the reduced size of blanking sheet could affect the yield strength of the product. The study of the yield strength and yield improvement of the product are done by simulating stress analysis by using CATIA software. The results show that the new proposed size of the metal blanking sheet provides accuracy of the product dimension as well as maintaining the yield strength of the product and it reduced a significant amount of metal scrap which is nearly $4 \%$ of material weight and save around $10 \%$ of inventory cost.
\end{abstract}

Key words: Metal Forming, Blanking, Yield Improvement, Metal Scrap

\section{INTRODUCTION}

Reducing sheet metal yield losses in automotive manufacturing would reduce material demand, providing both environmental and financial benefits. Steel Coil used in Stamping Shop will undergo several processes until finished product. Steel Coil are stored in the Coil Storage until it is transferred to the production line or the pressed. Approximately more than ten thousands Ringgit Malaysia losses due to the scraps generated from stamping shop [1].

The scraps generated after the Press Machine produced semi-finished product and being transferred into trimming, punching and piercing machines. The scraps will directly fall onto the scraps conveyor that operates beneath and moving towards the Baler Machine to be compressed. The trimming process alone will produce quite a lot of scrap metal that should be considered as material waste [2]. One way to reduce the metal scrap is by reducing the dimension of the blank panel especially the pitch or width that could still producing the same size products [3]. The idea is then being implemented into the production line and the study achieved a success. .

The yield improvement will definitely affect the Draw Die Guide panel in fitting the new blank metal sheet dimension or the reduced sized yield [4].
Therefore, by simulating the effect of stamping force onto the new blank panel by using CATIA finite element analysis will ensure the success of the new yield improvement result. The generative structural analysis between the current dimension and after yield reduction are important in determining result of stress test in understanding the performance of the products, products lifecycle and the failure mode possibility into the improvements made [5]. It may involve a complex design because any incorrect adjustment setting will damage the Draw Die machine resulting in financial losses to the company [6].

\section{METHODOLOGY}

The yield improvement study uses generative structural analysis which contain in the CATIA design workbench. The Generative structural analysis allows the designer to understand the structural behaviour and accurately measures the displacement and stresses under variety of loads. The advantage of using CATIA finite element analysis is it uses the same interface as the design environment and it can be easily identified the changes or improvement in design performance.

There are different types of steel coil for each part. The main differences are the width, pitch, thickness and weight of the coil. About 100 pieces of the blank sheet metal with current and reduced size dimension will be 
prepared for sampling test. The sample product that was produced after stamping process will then be checked for its formability, appearance and defects. After checking the sample products and the products free form defects, then the mass production sampling was implemented. During mass production test, 100 pieces of stamping products was continuously produced and checked for any defects. The collected data will be interpreted and will be presented in graphical method.

\section{The process flow}

1. The current size blank metal sheet are cut by specified proposed yield

2. The current size blank metal sheet and the yield reduction metal sheet are weighted to note the weight reduction

3. The yield reduction sheet metal will be used for trial test or sampling test

4. The produced part will be sent to Quality department to verify the dimensional accuracy

\section{RESULT AND DISCUSSION}

The analysis of yield improvement through generative structural analysis using CATIA software will help in interpreting the analyzed data and compare the result with the actual product produced in the production line. The main objective in carrying out the simulation analysis is to determine the suitability and feasibility of the proposed dimension of the new size of the blank panel. The analysis towards the blank panel is to study on the feasibility and the simulation is done based on the formation on the panel without any additional element which indicate natural formation on the panel towards the applied force [5]. There are three types of blank panels has been chosen which have different shapes. All of the panels are set to be applied with the same distributed force in a free formation mode. The amount of force is $26 \mathrm{kN}$ which represent the stamping force is applied in $\mathrm{z}$ direction which perpendicular to the surface of the panel [7]. The result of the analysis is based on Von Misses Stress which uses nodal values as the input. The meshing technique is set to be $20 \mathrm{~mm}$ in tetrahedron dimension. Figure 1.1 (a) and figure 1.1 (b) show the simulation results of the von misses stresses towards current dimension of the front fender blank panel and the new proposed dimension. The same analysis is applied to the other two panels which are the Hood outer panel and the trunk lid panel. The simulation result of the von misses stress towards the Hood outer and the trunk lid blank panels are shown in figure 1.2 (a), 1.2 (b), 1.3 (a) and 1.3 (b) respectively.

Based on the results of the generative structural analysis, the deformation status on the current and after yield are slightly different on the free formation on every edge of the panels. However they are still in acceptable range because the error are too small based on relative

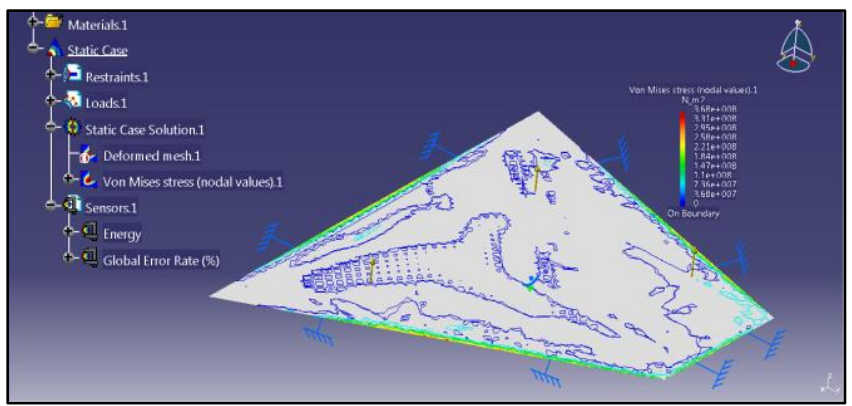

magnitude error readings which show error for Front Fender panel is $3.55 \mathrm{e}-10$, Hood outer panel is $2.87 \mathrm{e}-10$ and Trunk Lid panel is $0.51 \mathrm{e}-10$.

Figure 1.1 (a) Von Misses Stress Towards Current Yield Dimension of Front Fender

Figure 1.1 (b) Von Misses Stress Towards New Yield

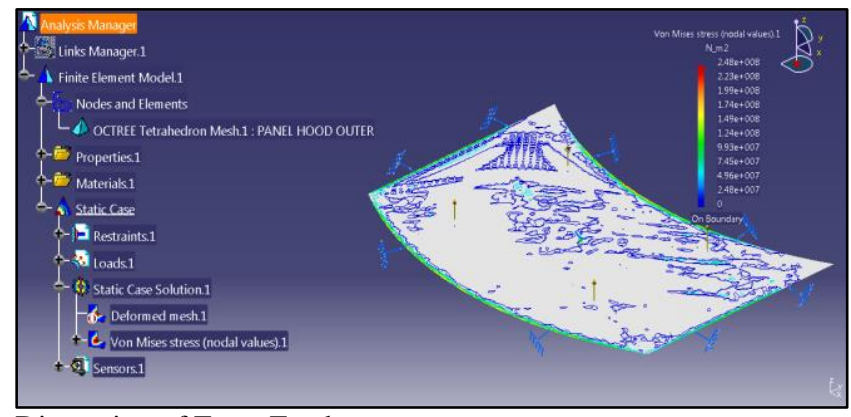

Dimension of Front Fender

Figure 1.2 (a) Von Misses Stress Towards Current Yield Dimension of Hood Outer

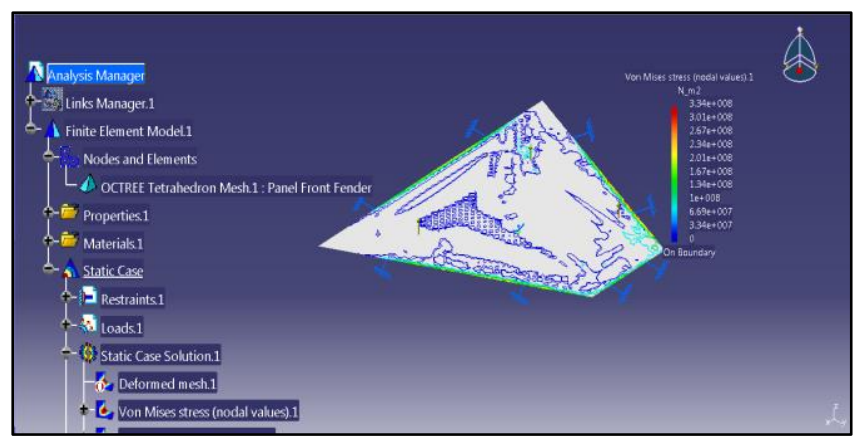

Figure 1.2 (b) : Von Misses Stress Towards New Yield Dimension of Hood Outer

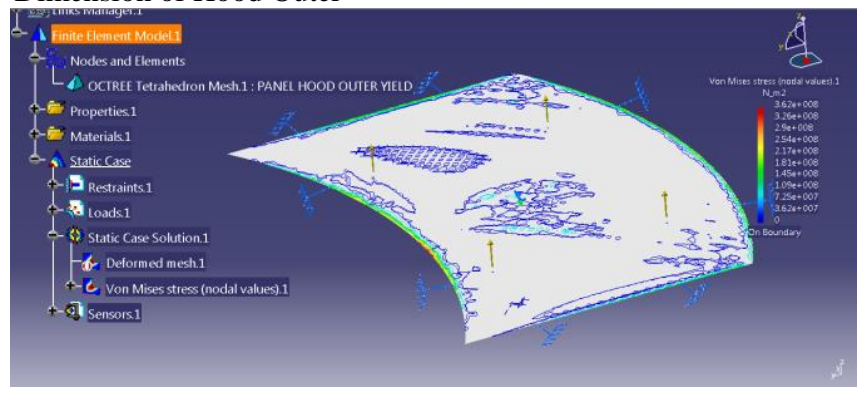




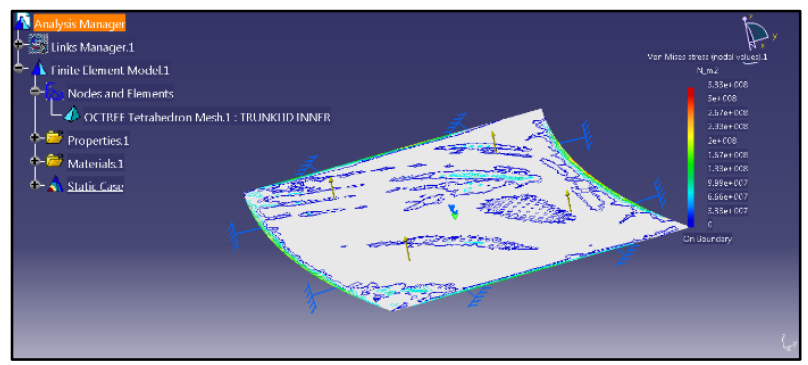

Figure 1.3 (a) Von Misses Stress Towards Current Yield Dimension of Trunk Lid

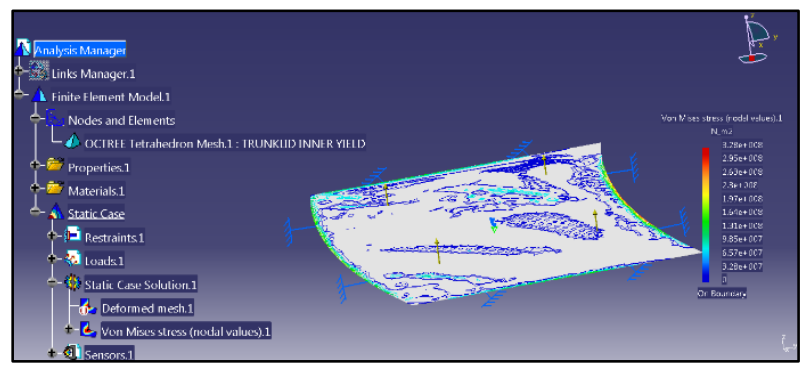

Figure 1.3 (b) Von Misses Stress Towards New Yield Dimension of Trunk Lid

Based on the generative structural analysis results, a new reduced yield dimension was proposed as shown in table 1.1 (b). Table 1.1 (a) shows the current yield dimension of Front Fender, Hood Outer and Trunk Lid panels.

\begin{tabular}{|c|l|c|c|c|}
\hline \multirow{2}{*}{ No } & \multirow{2}{*}{ Part Name } & \multicolumn{3}{|c|}{ Material Dimension (mm) - } \\
\cline { 3 - 5 } & & Width & Pitch & Thick \\
\hline 1 & $\begin{array}{l}\text { Panel Front } \\
\text { Fender }\end{array}$ & 1152 & 1485 & 0.65 \\
\hline 2 & $\begin{array}{l}\text { Panel Hood } \\
\text { Outer }\end{array}$ & 1660 & 1004 & 0.65 \\
\hline 3 & $\begin{array}{l}\text { Panel Trunk } \\
\text { Lid Inner }\end{array}$ & 1390 & 940 & 0.65 \\
\hline
\end{tabular}

Table 1.1 (a) : Current Yield dimension

\begin{tabular}{|c|l|c|c|c|}
\hline No & Part Name & \multicolumn{3}{|c|}{$\begin{array}{l}\text { Material Dimension (mm) - } \\
\text { Yield Reduction }\end{array}$} \\
\cline { 3 - 5 } & Width & Pitch & Thick \\
\hline 1 & $\begin{array}{l}\text { Panel Front } \\
\text { Fender }\end{array}$ & 1152 & 1463 & 0.65 \\
\hline 2 & $\begin{array}{l}\text { Panel Hood } \\
\text { Outer }\end{array}$ & 1637 & 992 & 0.65 \\
\hline 3 & $\begin{array}{l}\text { Panel Trunk } \\
\text { Lid Inner }\end{array}$ & 1390 & 900 & 0.65 \\
\hline
\end{tabular}

Table 1.1 (b): New dimension of Reduced Size Yield
The new proposed dimension was being used for trial purposes on the actual stamping machine. This is to ensure that the product quality does not being affected by the new reduced size yield dimension. Figure 2.1, figure 2.2 and figure 2.3 show the trial product of Front Fender, Hood Outer and Truck Lid respectively.

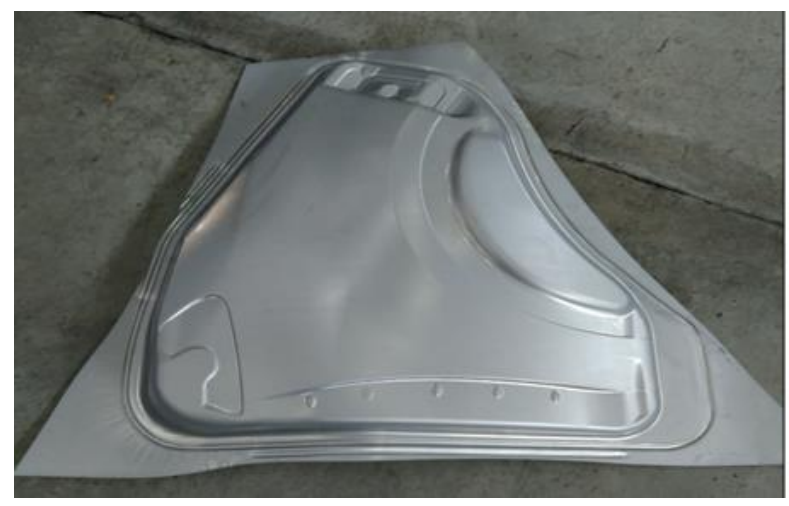

Figure 2.1 Trial product for Front Fender panel after yield reduction

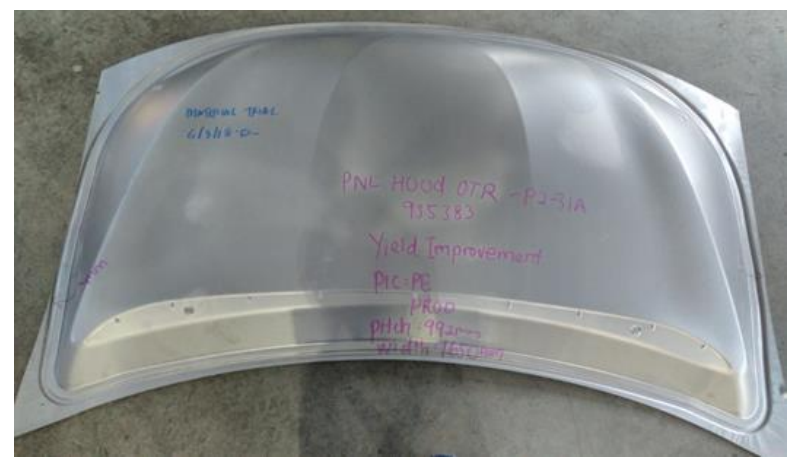

Figure 2.2 Trial product for Hood Outer panel after yield reduction

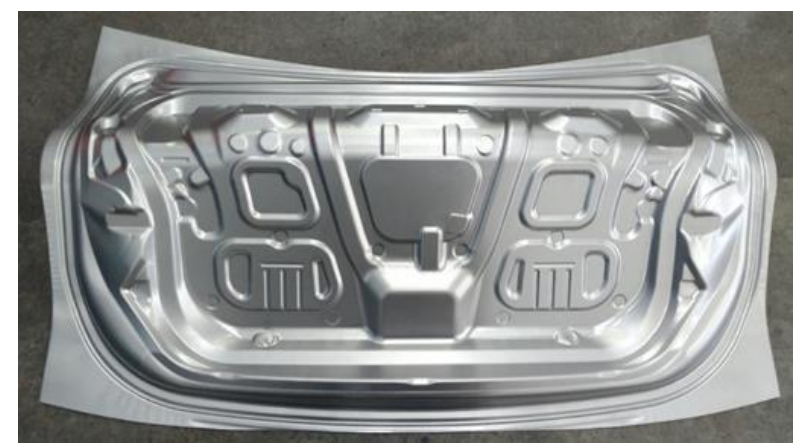

Figure 2.3 Trial product for Trunk Lid panel after yield reduction 
The sample product must be test for dimensional accuracy. In this study, the focus point for dimensional accuracy are the hole, trim line and gap dimension. There are several points in each of panels with different numbers of checking points. Figure 3.1 shows the checking points on the Outer Hood panel. There should be less than $5 \%$ error of dimensional accuracy before the sample product should be accepted. The dimensional accuracy reading for Front Fender panel, Hood Outer Panel and Trunk Lid Panel are shown in table 2.1, 2.2 and 2.3 respectively.

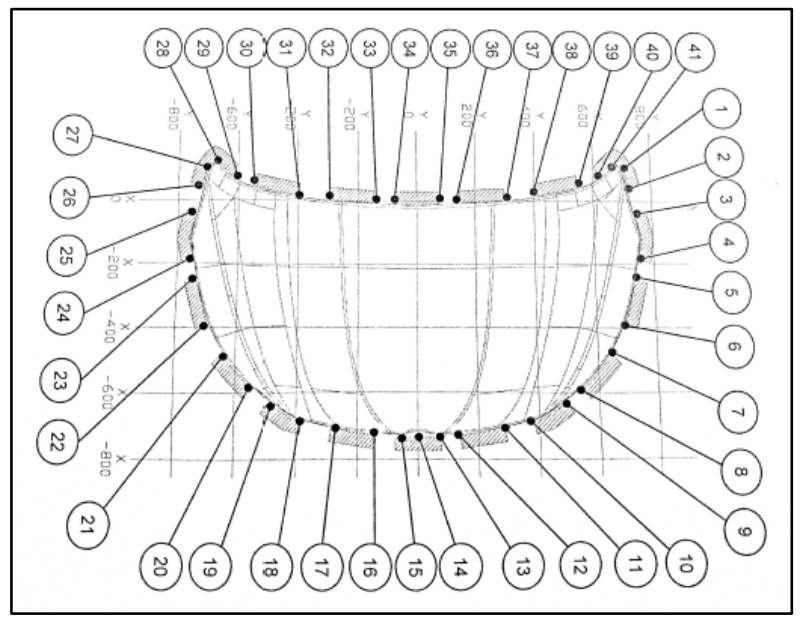

Figure 3.1 Dimensional accuracy checking points of Hood Outer panel

\begin{tabular}{|c|c|c|c|}
\hline ITEM & $\begin{array}{c}\text { POINT } \\
\text { OK }\end{array}$ & $\begin{array}{c}\text { TOTAL } \\
\text { POINT }\end{array}$ & ACCURACY (\%) \\
\hline GAP & 89 & 96 & 92.7 \\
\hline TRIM & 95 & 96 & 98.9 \\
\hline HOLE & 53 & 56 & 94.64 \\
\hline
\end{tabular}

Table 2.1 Dimensional accuracy data on Front Fender panel

\begin{tabular}{|c|c|c|c|}
\hline ITEM & $\begin{array}{c}\text { POINT } \\
\text { OK }\end{array}$ & $\begin{array}{c}\text { TOTAL } \\
\text { POINT }\end{array}$ & $\begin{array}{c}\text { ACCURACY } \\
(\%)\end{array}$ \\
\hline GAP & 55 & 61 & 90.16 \\
\hline TRIM & 40 & 41 & 97.6 \\
\hline HOLE & - & - & - \\
\hline
\end{tabular}

Table 2.2 Dimensional accuracy data on Hood Outer panel

\begin{tabular}{|c|c|c|c|}
\hline ITEM & $\begin{array}{c}\text { POINT } \\
\text { OK }\end{array}$ & $\begin{array}{c}\text { TOTAL } \\
\text { POINT }\end{array}$ & $\begin{array}{c}\text { ACCURACY } \\
(\%)\end{array}$ \\
\hline GAP & 148 & 154 & 96.1 \\
\hline TRIM & 130 & 136 & 95.6 \\
\hline HOLE & 185 & 188 & 98.4 \\
\hline
\end{tabular}

Table 2.3: Dimensional accuracy data on Trunk Lid panel
In order to obtain the amount of metal scrap reduction, all of the panels had gone through weighing scale. The weight of the panels was obtained before and after yield improvement has been made. The weight reduction percentage of the Front Panel is $3.95 \%$, the Hood Outer is $4.03 \%$ and the Trunk Lid is $2.83 \%$. Table 3.1 shows the data collection on weight changes and material saving percentages. The weight reduction percentage was obtained by using the following Formula:

$$
\frac{\text { Reduction }(\mathrm{kg})}{\text { Current material weight }(\mathrm{kg})} \times 100
$$

\begin{tabular}{|c|c|c|c|c|}
\hline \multirow{2}{*}{$\begin{array}{c}\text { Part } \\
\text { Name }\end{array}$} & Current & $\begin{array}{c}\text { After } \\
\text { Yield } \\
\text { Reducti } \\
\text { on }\end{array}$ & $\begin{array}{c}\text { Reducti } \\
\text { on(kg)/ } \\
\text { pcs }\end{array}$ & $\begin{array}{c}\text { Material } \\
\text { Saving } \\
\text { percentage } \\
/ \mathrm{pcs}\end{array}$ \\
\hline $\begin{array}{c}\text { Panel } \\
\text { Front } \\
\text { Fender }\end{array}$ & 5.826 & 5.596 & 0.23 & $3.95 \%$ \\
\hline $\begin{array}{c}\text { Panel } \\
\text { Hood } \\
\text { Outer }\end{array}$ & 8.43 & 8.09 & 0.34 & $4.033 \%$ \\
\hline $\begin{array}{c}\text { Panel } \\
\text { Trunk } \\
\text { Lid } \\
\text { Inner }\end{array}$ & 6.4735 & 6.2905 & 0.183 & $2.83 \%$ \\
\hline \multicolumn{2}{|c|}{} & & & \\
\hline
\end{tabular}

Table 3.1 The data collection on weight changes and material saving percentages

\section{CONCLUSION}

Based on the study of generative structural analysis, new yield dimension has been identified to be used as a reduced size yield that has the same capability as the current yield dimension to produce parts that meets the product quality requirements with minimum error of less than $0.1 \%$. The actual stamping part of Front Fender, Hood Outer and Trunk Lid panels had been produced as a sample. All of the sample has gone through quality check to check several important points in order to ensure the accurate measurement of the products dimension. All of the quality check meets 90\% accuracy. The new yield dimension gives material saving for about $4 \%$ for each panel. A total of $10 \%$ weight reduction represent the total saving in inventory cost in terms of steel coil [8].

\section{ACKNOWLEDGMENTS}

The authors acknowledge the financial support from Politeknik Sultan Azlan Shah, Behrang, Perak. 


\section{REFERENCES}

[1] Hian Chye Koh, Khim Ling Sim, and Larry N. Killough (2004). The Interaction Effects of Lean Production Manufacuring Practices, Compensation, and Information Systems on Production Costs, Research Paper Published by Journal of Advances in Management Accounting, Vol.12, pp.115-135.

[2] Khalil A. El-Namrouty, Mohammed S. AbuShaaban. Seven Wastes Elimination Targeted by Lean Manufacturing Case Study "Gaza Strip Manufacturing Firms", International Journal of Economics, Finance and Management Sciences. Vol. 1, No. 2, 2013, pp. 68-80.

[3] Abdullah, F., (2003). Lean Manufacturing Tools and Techniques in the Process industry with a focus on Steel, $\mathrm{PhD}$ thesis, University of Pittsburgh.

[4] Aniket N. Patil, Prof. V. L. Kadlag.(2016). Blanking Process Optimization using Finite Element Analysis \& Taguchi Method.Abstract. www.ijste.org/articles/IJSTEV2I12254.pdf
[5] Len Watson.(2008). Boron Steel in Vehicles.Boron Steel in Vehicles.

[6] Drishtikona.(2012).Sheet Metal Stamping in Automotive Industry.Blanking for Panel Stamping and Tailored Blanks. 6 -7.

[7] Ivana Suchy.(2006). Blanking and Piercing Operations. Metal Cutting Process. https://www.globalspec.com/reference/63584/2032 79/chapter-6-blanking-and-piercing-operations

[8] Kazuhiro Yamashita, (2004). Implementation of Lean Manufacturing Process to XYZ Company in Minneapolis Area, Master Thesis, University of Wisconsin-Stout. 